\title{
Differences in the male calling songs of two sibling species of Cicada (Hemiptera: Cicadoidea) in Greece
}

\author{
Paula C. Simões ${ }^{1}$, Michel Boulard ${ }^{4}$, Maria T. REBelo ${ }^{1}$, Sakis DROSOPOUlOS $^{3}$, Michael F. ClaridgE ${ }^{2}$, \\ JoHN C. MORGAN² and José A. QUARTAU ${ }^{1 *}$
}

${ }^{1}$ Centro de Biologia Ambiental, Departamento de Zoologia \& Antropologia, C2-3 Piso, Faculdade de Ciências de Lisboa, Campo Grande, 1700 Lisboa, Portugal

${ }^{2}$ School of Biosciences, University of Wales, Cardiff, CFTL, UK

${ }^{3}$ Agricultural University of Athens, Department of Agricultural Biology and Biotechnology, Iera odos 75, Votanicos, 11855 Athens, Greece

${ }^{4}$ EPHE, Biologie et Évolution des Insectes, Muséum national d'Histoire Naturelle, 45 rue Buffon, 75005 Paris, France

Key words. Cicada mordoganensis, Cicada orni, acoustic signals, acoustic divergence, calling songs, Greece

\begin{abstract}
Cicada orni L. is one of the most abundant and common species of cicada in Greece. However, this species was not found during recent field work on the Greek islands of Samos and Ikaria. Instead, the very closely related C. mordoganensis Boulard was found practically everywhere on these islands. C. orni and C. mordoganensis are very closely related species which are morphologically very similar (sibling species), even the male genitalia, and the acoustic signals produced by males during courtship and pair formation have the same general pattern. In order to describe the acoustic signals produced by these sibling species, temporal and spectral analyses were made of the calling songs of the males and certain acoustic variables were measured. Based on the duration of echemes, the number of pulse units they contain, the intervals between echemes and the number of echemes per second, the song of C. mordoganensis is distinct from that of $C$. orni. Cluster analysis of the acoustic characteristics of C. mordoganensis from Samos and Ikaria and of C. orni from the Greek mainland (Dionysos, north of Athens) gave a clear and distinct separation of these species.

Moreover, as there has been very little divergence between these two species at the protein electrophoretic level, the acoustic divergence has evolved independently of allozyme divergence. This may imply that in these cicadas acoustic divergence, and therefore premating isolation, may have evolved rapidly and resulted in rapid speciation at low levels of general genetic differentiation.
\end{abstract}

\section{INTRODUCTION}

Cicada orni $\mathbf{L}$. is one of the most abundant and common species of cicadas on the mainland of Greece (Quartau et al., 1999). However, this species was not found on the islands of Samos and Ikaria during recent field work there in July of 1997, 1998 and 1999. Instead, a calling song reminiscent of that of C. orni was heard practically everywhere. Examination of the genitalia of a few males producing this song revealed that they belong to Cicada mordoganensis Boulard, a species very close to $C$. orni and previously known only from Turkey (Boulard, 1979). Fig. 1 is the left lateral view of the male genital segments of a specimen of $C$. mordoganensis from Samos which closely resemble those of C. orni. Fig. 2 is that of a specimen of C. orni collected on the Greek mainland (Dionysos, north of Athens).

C. mordoganensis and C. orni are morphologically very similar, even the male genitalia, and the songs of the males have the same general pattern: a repetitive series of separate sound elements, each one consisting of a series of rapidly and regularly reproduced pulses (Boulard, 1979, 1995; Quartau et al., 1999). In order to accurately describe the differences in the calling songs of the males of these sibling species, temporal and spectral analyses were made of their songs, certain acoustic variables were measured, and cluster analysis applied to the results.

\section{MATERIAL AND METHODS}

The male calling songs of several specimens of both species were recorded in the field at temperatures of about 32 to $33^{\circ} \mathrm{C}$ on the Greek islands of Samos and Ikaria and on the mainland at
Dionysos, north of Athens. These recordings were made in the frequency range between $50 \mathrm{~Hz}$ and $18 \mathrm{kHz}$ on a digital Sony Dat recorder connected to a compatible dynamic microphone (Sony F-780) responding to the same frequency range. Songs of 20 males of $C$. mordoganensis (ten from Ikaria and ten from Samos) and ten males of C. orni (Dionysos, north of Athens) were analysed.

As in Quartau et al. (1999), the terminology used to describe the songs is that of Gogala et al. (1996). The recordings were subjected to time and frequency-based analyses, i.e., the songs were converted into oscillograms, sonagrams and spectrograms (frequency spectra) by using a Digital Audio Card and the software Cool Edit 96 and Avisoft SASLab Light 97. For each specimen, recordings of about 20 seconds were analysed and the following acoustic variables were measured: duration of each echeme based on a sample of 15 , number of pulse units in each echeme in the same sample of 15 , duration of the 15 intervals between echemes, number of echemes per second in the recording of 20 seconds, and the range in frequencies with the highest energy, together with the highest energy values (Table 1).

Cluster analysis was applied to the songs of C. mordoganensis and $C$. orni. As clustering algorithm the UPGMA method based on a similarity matrix of Euclidean distances with standardized data was performed. The following five acoustic parameters were used as variables: duration of echemes, number of pulse units per echeme, number of echemes per second, interval between echemes and the frequency with highest

\footnotetext{
* Author for correspondence.
} 

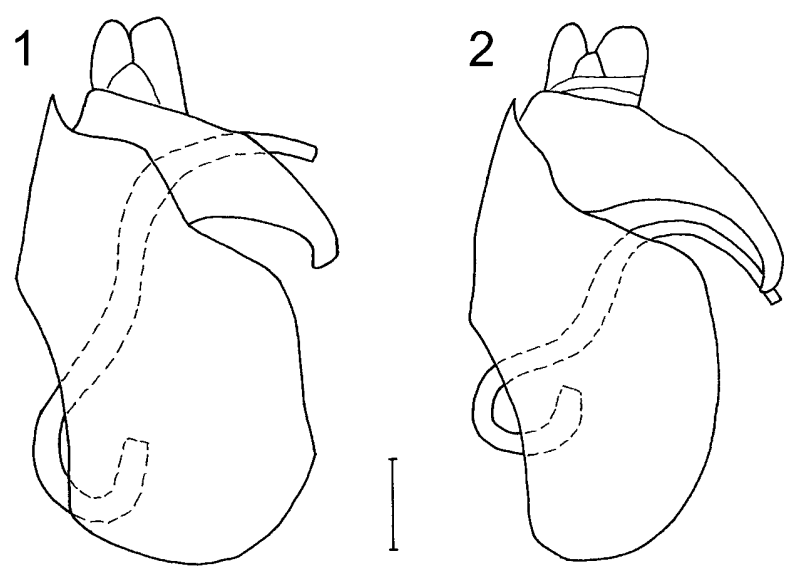

Figs 1-2: Left lateral view of the genital segments of a male. 1 - C. mordoganensis Boulard from Samos; 2 - C. lorni L. from Dionysos, Athens. Scale $=0.8 \mathrm{~mm}$.

energy.

\section{RESULTS}

Oscillograms, sonagrams and spectrograms of the songs of $C$. mordoganensis and C. orni are given in Figs 3-10, and a summary of each of the temporal and spectral characteristics in Table 1.

A comparison of the two songs showed that in spite of having a common basic pattern, the songs differ in their temporal parameters, even at similar temperatures. In C. mordoganensis the duration of the echemes are longer (mean of $0.392 \mathrm{~s} \pm 0.065$ vs. $0.093 \mathrm{~s} \pm 0.031$ ), the number of pulses within each echeme

\section{corranumanum} 3)

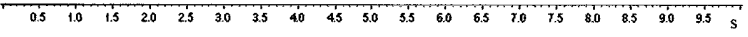

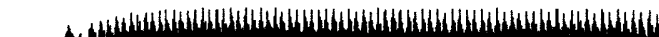

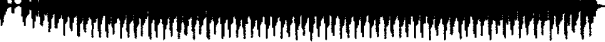

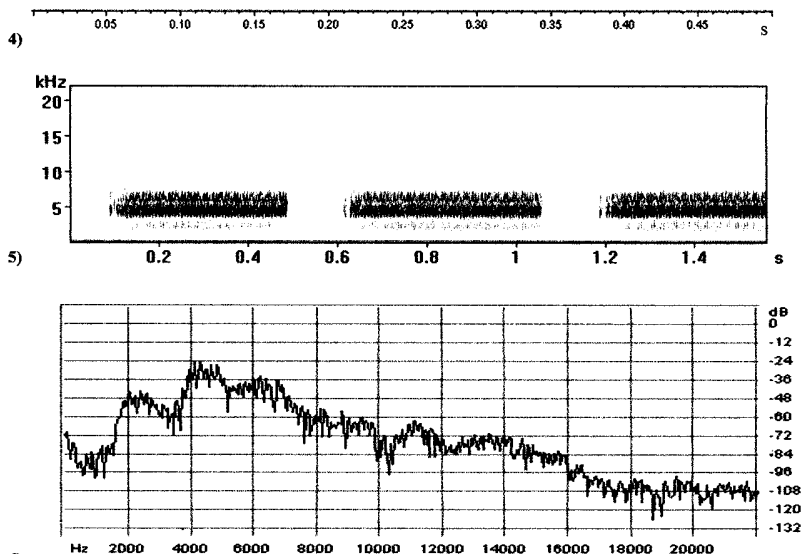

Figs 3-6. Song of a male of C. mordoganensis Boulard (Samos). 3 - oscillogram over a period of $10 \mathrm{~s} ; 4$ - oscillogram with an extended time-base of $0.5 \mathrm{~s} ; 5$ - sonagram over a period of $1.55 \mathrm{~s} ; 6$ - spectrogram. higher (mean $75.539 \pm 12.974$ vs. $18.56 \pm 5.675$ ), the intervals between echemes shorter (mean $0.126 \mathrm{~s} \pm 0.041$ vs. $0.259 \mathrm{~s} \pm$ 0.107 ), and the number of echemes per second much lower $(1.969 \pm 0.181$ vs. $2.923 \pm 0.666)$ than in $C$. orni. Differences proved to be highly significant $(\mathrm{P}<0.005)$ in the duration of echemes, the number of pulses per echeme, the intervals between echemes and the number of echemes per second.

The spectral characteristics are, however, similar: Frequencies with the highest energy range from 3.985 to $4.795 \mathrm{kHz}$ (mean of $4.355 \pm 0.213$ ) for $C$. mordoganensis, and from $4.158 \mathrm{kHz}$ to 5.876 (mean of $4.780 \pm 0.549$ ) for C. orni.

The dendrogram based on a UPGMA cluster analysis using five acoustic parameters as characters is given in Fig. 11. This analysis resulted in two major clusters, corroborating the existence of two species, one corresponds to the acoustic signals produced by the Samos and Ikaria males (C. mordoganensis) and the second to those produced by males of $C$. orni from the Greek mainland.

\section{CONCLUSIONS AND DISCUSSION}

Males of C. mordoganensis were heard practically everywhere during recent field work on the islands of Samos and Ikaria and, like $C$. orni, they frequently sing in chorus producing the loud cicada sound so typical of a Mediterranean summer.

The chorus probably indicates that the song may have a social role, as in some African cicadas (Villet, 1992), in addition to its primary in attraction and mate recognition (e.g., Claridge et al. 1979; Claridge, 1985; Paterson, 1985).

The time and frequency-based analyses of the songs of these species showed that they differed in their temporal parameters,

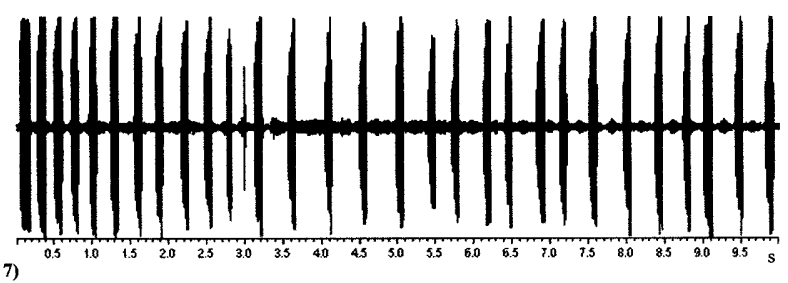

7)

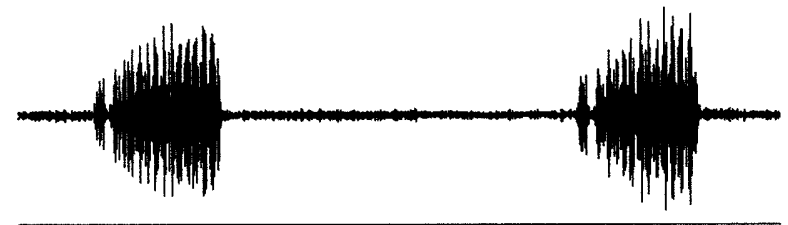

8)
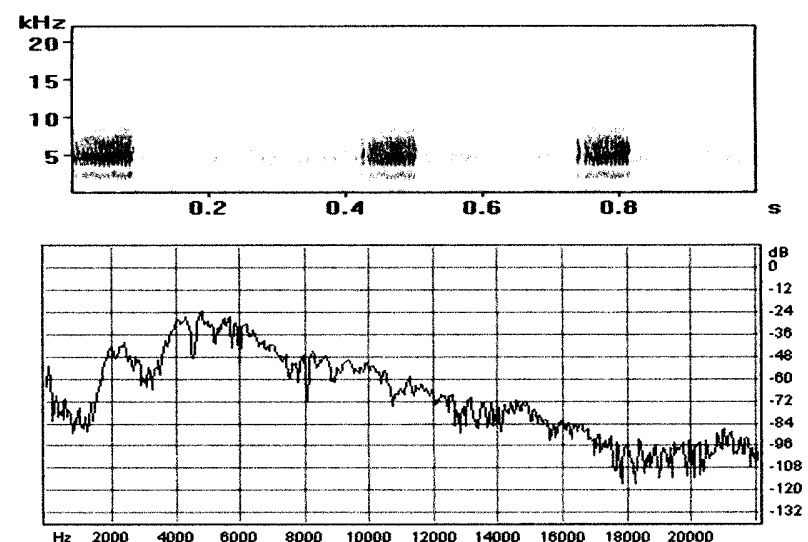

10)

Figs 7-10. Song of a male of C. orni L. (Dionysos, Athens). 7 - oscillogram over a period of $10 \mathrm{~s} ; 8$ - oscillogram with an extended time-base of $0.5 \mathrm{~s} ; 9$ - sonagram over a period of 1.0 s; 10 - spectrogram. 
TABLE 1. Acoustic parameters of populations of C. mordoganensis Boulard (Samos and Ikaria) and C. orni L. (Dionysos, Athens).

\begin{tabular}{llccccc}
\hline & & Duration of echemes (s) Pulse units/echeme & $\begin{array}{c}\text { Interval between } \\
\text { echemes }(\mathrm{s})\end{array}$ & No. of echemes/s & $\begin{array}{c}\text { Freq. with highest } \\
\text { energy }(\mathrm{kHz})\end{array}$ \\
\hline SAMOS & range & $0.263-0.561$ & $46-112$ & $0.047-0.308$ & $1.572-2.182$ & $3.985-4.497$ \\
& $\mathrm{~m} \pm \mathrm{sd}$ & $0.406 \pm 0.059$ & $80.08 \pm 10.789$ & $0.116 \pm 0.030$ & $1.967 \pm 0.173$ & $4.259 \pm 0.182$ \\
& $\mathrm{n}$ & 10 & 10 & 10 & 10 & 10 \\
IKARIA & range & $0.217-0.616$ & $40-108$ & $0.061-0.312$ & $1.717-2.360$ & $4.148-4.795$ \\
& $\mathrm{~m} \pm \mathrm{sd}$ & $0.379 \pm 0.068$ & $71.18 \pm 13.442$ & $0.135 \pm 0.047$ & $1.970 \pm 0.197$ & $4.451 \pm 0.206$ \\
& $\mathrm{n}$ & 10 & 10 & 10 & 10 & 10 \\
TOTAL & range & $0.217-0.616$ & $40-112$ & $0.047-0.312$ & $1.572-2.360$ & $3.985-4.795$ \\
& $\mathrm{~m} \pm \mathrm{sd}$ & $0.392 \pm 0.065$ & $75.539 \pm 12.974$ & $0.126 \pm 0.041$ & $1.969 \pm 0.181$ & $4.355 \pm 0.213$ \\
& $\mathrm{n}$ & 20 & 20 & 20 & 20 & 20 \\
DIONYSOS & range & $0.045-0.225$ & $8-36$ & $0.081-0.551$ & $2.393-3.843$ & $4.158-5.876$ \\
(ATHENS) & $\mathrm{m} \pm \mathrm{sd}$ & $0.093 \pm 0.031$ & $18.56 \pm 5.675$ & $0.259 \pm 0.107$ & $2.923 \pm 0.666$ & $4.780 \pm 0.549$ \\
& $\mathrm{n}$ & 10 & 10 & 10 & 10 & 10 \\
\hline
\end{tabular}

even at similar temperatures. In fact, there are significant differences $(\mathrm{P}<0.005)$ in the interval between echemes, the duration of echemes, the number of pulses per echeme and the number of echemes per second. However, the spectral characteristics are very similar.

The dendrogram based on a UPGMA indicated two clusters, which suggests the existence of two species.

These results indicate that the calling songs of these species are quite distinct, but have the same general pattern. Moreover, as the species are similar morphologically, this is another example of the best way to discriminate between cicadas which is to use the male song as a taxonomic character (Quartau, 1995).

It is also interesting to note that these sibling species are even closer genetically than $C$. orni and C. barbara (Quartau et al., 2000). This is revealed by an analysis of 13 enzyme systems in these species (Seabra et al., 2000). Of the 19 loci studied none were found to be diagnostic. It seems, therefore, that differences in these songs have evolved independently of allozyme divergence. That is, in these cicadas acoustic differences and there- fore premating isolation may have evolved rapidly and resulted in rapid speciation at low levels of general genetic differentiaion

ACKNOWLEDGEMENTS. We appreciate the help of A. Genage (Departmento de Zoologia e Antropologia, Faculdade de Ciências de Lisboa), both in the field and in the laboratory. The authors also thank the reviewers for their helpful comments, which greatly improved the manuscript. This study was partially supported by project PRAXIS 2/2.1/BIA/97/94 (Praxis XXI, Lisbon).

\section{REFERENCES}

Boulard M. 1979: Cigales du genre Cicada Linné, originaires de Turquie (Hom. Cicadidae). Tuerk Bit. Kor. Dergisi 3(2): $67-74$.

Bovlard M. 1995: Postures de cymbalisation, cymbalisations et cartes d'identité acoustiques de cigales. 1. Généralités et espèces méditerranéennes (Homoptera, Cicadoidea). EPHE, Biol. Évol. Insectes $7 / 8$ : 1-72.

\section{Euclidean distances}

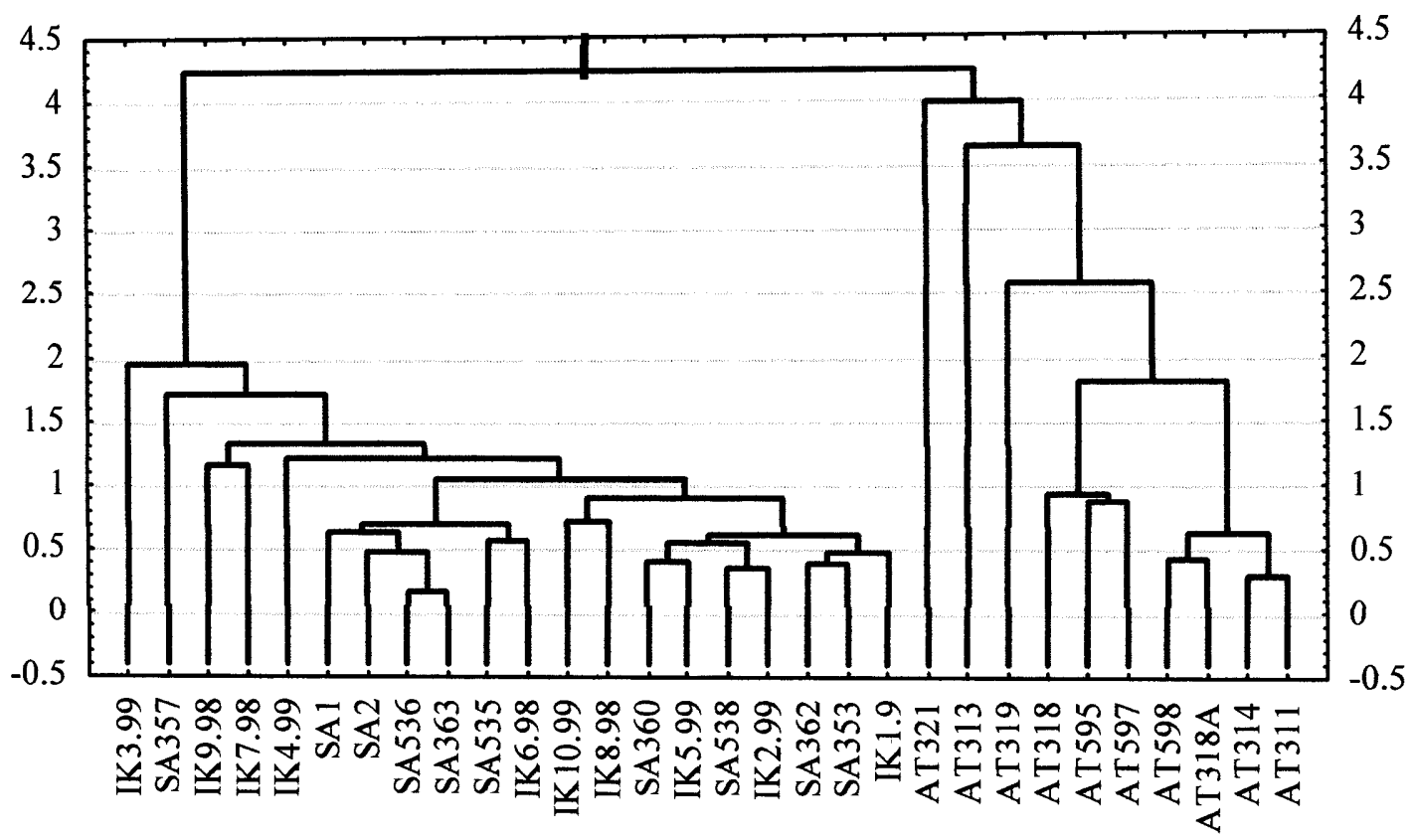

Fig. 11. Dendrogram of the relationships between 20 males of $C$. mordoganensis Boulard from Samos and Ikaria and 10 males of C. orni L. from Athens, revealed by UPGMA cluster analysis of Euclidean distances. Data standardized. IK - Ikaria; SA - Samos; AT -Athens; numbers refer to specimens. 
Claridge M.F. 1985: Acoustic signals in the Homoptera: behaviour, taxonomy, and evolution. Annu. Rev. Entomol. 30: 297-317.

Claridge M.F., Wilson M.R. \& Singhrao J.S. 1979: The songs and calling sites of two European cicadas. Ecol. Entomol. 4 225-229.

Gogala M., Popov A.V. \& Ribaric D. 1996: Bioacoustics of singing cicadas of the western Palaearctic: Cicadetta tibialis (Panger) (Cicadoidea: Tibicinidae). Acta Entomol. Sloven. 4 : $45-62$.

Paterson H.E. 1985: The recognition concept of species. In Vrba E.S (ed.): Species and Speciation. Transvaal Museum Monograph No. 4, Pretoria, pp. 21-29.

QUARTAU J.A. 1995: Cigarras, esses insectos quase desconhecidos. Correio Natur. 19: 33-38.

Quartau J.A. \& Rebelo M.T. 1991: Sinais acústicos em Cicadidae e Cicadellidae (Homoptera, Auchenorrhyncha) que ocorrem em Portugal. In Almada V. \& Oliveira R. (eds): Actas do $1^{\circ}$ Congresso Nacional de Etologia. Instituto Supe- rior de Psicologia Aplicada, Lisboa, pp. 137-142.

Quartau J.A., Rebelo M.T., Simões P.C., Fernandes T.M., Clardgge M.F., Drosopoulos S. \& Morgan J.C. 1999: Acoustic signals of populations of Cicada orni L. in Portugal and Greece (Homoptera: Auchenorrhyncha: Cicadomorpha: Cicadidae). Reichenbachia 33: 71-80.

Quartau J.A., Ribeiro M., Simões P.C. \& Crespo A. 2000 Taxonomic separation by isozyme electrophoresis of two closely related species of Cicada L. (Hemiptera: Cicadoidea) in Portugal. J. Nat. Hist. (in press).

Seabra S., Smões P.C., Drosopoulos S. \& Quartau J.A. 2000; Genetic variability and differentiation in two allopatric species of the genus Cicada L. (Hemiptera: Cicadoidea) in Greece. Dt. Entomol. Z. (in press).

VILLET M. 1992: Response of free-living cicadas (Homoptera: Cicadidae) to broadcasts of cicada songs. J. Entomol. Soc. Sth. Afr. 55: 93-97.

Received November 16, 1999; accepted February 25, 2000 